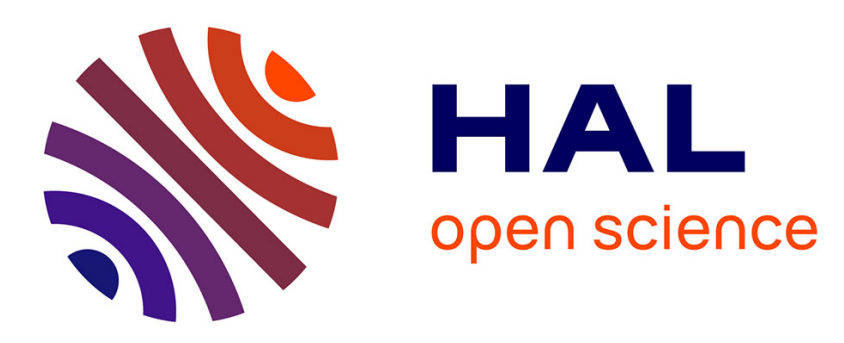

\title{
Needle positioning in interventional MRI procedure: real time optical localisation and accordance with the roadmap.
}

\author{
Romain Viard, Nacim Betrouni, Jean Rousseau, Serge R. Mordon, Olivier
} Ernst, Salah Maouche

\section{To cite this version:}

Romain Viard, Nacim Betrouni, Jean Rousseau, Serge R. Mordon, Olivier Ernst, et al.. Needle positioning in interventional MRI procedure: real time optical localisation and accordance with the roadmap.. Conference proceedings: .. Annual International Conference of the IEEE Engineering in Medicine and Biology Society. IEEE Engineering in Medicine and Biology Society. Annual Conference, 2007, 1, pp.2748-51. 10.1109/IEMBS.2007.4352897 . inserm-00192867

\section{HAL Id: inserm-00192867 https://www.hal.inserm.fr/inserm-00192867}

Submitted on 29 Nov 2007

HAL is a multi-disciplinary open access archive for the deposit and dissemination of scientific research documents, whether they are published or not. The documents may come from teaching and research institutions in France or abroad, or from public or private research centers.
L'archive ouverte pluridisciplinaire HAL, est destinée au dépôt et à la diffusion de documents scientifiques de niveau recherche, publiés ou non, émanant des établissements d'enseignement et de recherche français ou étrangers, des laboratoires publics ou privés. 


\title{
Needle positioning in interventional MRI procedure: real time optical localisation and accordance with the roadmap.
}

\author{
Romain Viard, Nacim Betrouni, Member, IEEE, Jean Rousseau, Member, IEEE, Serge Mordon, \\ Olivier Ernst, Salah Maouche
}

\begin{abstract}
This study presents a system designed to assist the surgeon during interventional procedures performed by Magnetic Resonance Imaging (MRI). In order to reach the target during guidance in a double obliquity trajectory, this system provides accurate information about both the entry point and the orientation of the needle.
\end{abstract}

\section{INTRODUCTION}

$T^{\mathrm{s}}$ Thanks to its high contrast to soft tissues and to the absence of ionizing radiations, Magnetic Resonance Imaging is a well adapted modality for interventional practice. MRI is more and more often used to guide instruments during interstitial procedures and to peroperatively monitor a treatment. The use of MRI in performing minimally invasive procedures is probably one of the most promising futures for this imaging modality. Although many research teams work on this field, lots of problems still subsist and have approximate surgical procedures as outcome. The success of an interventional gesture depends on the accuracy of the needle tip reaching the target site. Tracking requires fast and accurate measures of the instrument position for guiding needle insertion procedures.

Nowadays several methods have already been proposed, each has provided his own trade-off between 3Dcoordinate update, easiness of implementation, constraints related to the nature of the trajectories (orthogonal or oblique, simple or double obliquity, rectilinear or curve)... Choice is made according to the kind of procedure.

For example, vascular interventions require sophisticated techniques with active MR device tracking [1] [2]. However, biopsies impose only moderate requirements on update rate. Furthermore needles are relatively stiff and short, enabling the use of passive detection and/or optical localisation. Passive tracking is relatively slow and artefact sensitive because image segmentation is required [3]. For external localization, stereovision systems have been particularly used. Luminous markers (led, reflective balls...) fixed on the instrument are detected [4].

Two commercial solutions have recently appeared on the market: a robotic system for closed MR scanner "Innomotion system" (Innomedic - Germany) [5;6], and a 3D locator system namely "endoscout" (Robin Medical Nesher, Israël).

In this study we present a system designed to guide interventional procedures performed by MRI. In order to reach the target during guidance in a double obliquity trajectory, this system provides accurate information about both the entry point on the patient's skin and the orientation of the needle.

\section{MAterials AND MethodS}

\section{A. $M R I$}

The study was carried-out on an AIRIS MATE scanner (Hitachi ${ }^{\circledR}$ Medical Co., Chiba, Japan). This 0.2 Tesla open MR Imaging system, with a panoramic Open Gantry design and permanent magnet, is highly suited for interventional MRI procedures. Its horizontal open-bore configuration (vertical magnetic field) allows simultaneous imaging and patient access.

Manuscript received April 2, 2007. Grants were awarded by the RNTS 2005 research program (ANR05RNTS01901), by the "Institut National de la Santé et de la Recherche Médicale" (U 703 Inserm), by the University Hospital of Lille, by the "Conseil Régional Nord-Pas de Calais" (CPER 2000-2006 Médecine interactive) and by the "Ministère de l'Education Nationale, de la Recherche et de la Technologie" (UPRES EA 1049).

R. Viard is with Inserm, U703, Lille, France (e-mail: r-viard@chru-lille.fr) and with LAGIS, Automatic Laboratory, USTL, France.

N. Betrouni and J. Rousseau are with Inserm, U703, Lille, France (e-mail: jrousseau@chru-lille.fr and n-betrouni@chru-lille.fr )

S. Mordon is with INSERM, IFR 114, Lille University Hospital, Lille, France (e-mail: mordon@lille.inserm.fr )

O. Ernst is with the interventional radiology department, Lille University Hospital, Lille, France (e-mail: oernst@chru-lille.fr )

S. Maouche is with LAGIS, Automatic Laboratory, USTL, France (e-mail : Salah.Maouche@univ-lille1.fr). 


\section{B. Roadmap planning}

The needle positioning system is designed to be interfaced with a house-made software written in Borland $\mathrm{C}++$ Builder ${ }^{\circledR}$ and implemented on standard PC. This software has been developed by our laboratory (http://www.u703.fr/) for general or specific medical image processing to Computer Aided Diagnosis (CAD) or Surgery (CAS) applications.

The needle insertion point and the target site are defined on MR images inside the homogeneous area of the main magnetic field (Fig 1). These two points defined the linear trajectory (double-obliquity). Their 3D coordinates in the MRI's coordinate system are computed using DICOM header. Three-dimensional imaging is used for target visualization, insertion planning and validation of the roadmap.

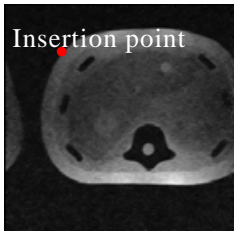

(a)

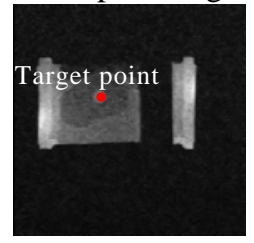

(b)

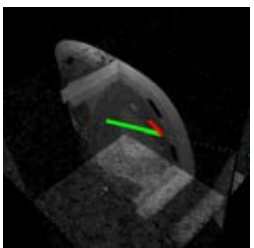

(c)

Fig. 1: Anatomical images are used to define the roadmap.

(a) Axial plane

(b) Sagittal plane

(c) 3D-view of the roadmap

\section{Indication of the needle insertion point}

In order to highlight the needle insertion point on the patient's skin, the pen of the A3-size pen plotter (MP303-04 Graphtec $^{\circledR}$, Yokohama, Japan) was substituted by a laser pointing device (Fig. 2). The pointer displacement was controlled by a host microcomputer, located outside the magnet room.

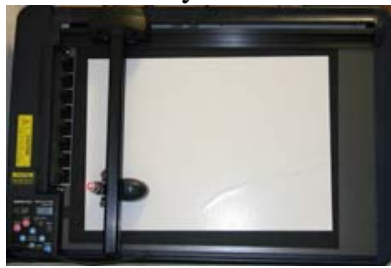

(a)

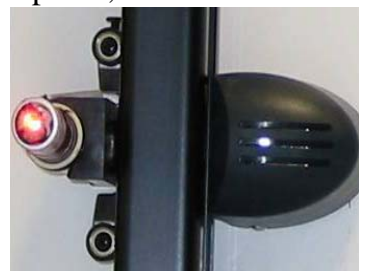

(b)

Fig. 2.

(a) Pen plotter hung on the wall in front of the MRI scanner (3 meters).

(b) Enlargement of the red laser pointer which substituted the colour pen.

\section{Calibration of the stereovision system}

We have installed a stereovision system including 4 monochromic CCD video cameras (512 X 512 pixels), sensitive to infra-red radiation. The cameras are calibrated using a calibration frame with a plan composed of gadolinium sphere. MR images of the external calibration frame (Fig 3) provide 3D coordinates (MRI's coordinate system) which were paired with 2D-coordinates of each camera (camera's coordinate system) [7] [8] . The plan can be installed in 4 positions what provides 64 reference points. These points permitted to solve, using the singular value decomposition method (SVD), the system:

$$
\left(\begin{array}{l}
u \\
v \\
1
\end{array}\right)=M\left(\begin{array}{l}
x \\
y \\
z \\
1
\end{array}\right)
$$

Equation(1) :

Where $\mathrm{M}$ is the homogenous matrix of each camera

$(\mathrm{x}, \mathrm{y}, \mathrm{z})$ coordinates of a sphere in MR coordinate system and $(\mathrm{u}, \mathrm{v})$ the coordinates of its projection on the camera image.

Homogenous matrix was computed for each camera [9]. The MRI's coordinate system was used as common coordinate system. 


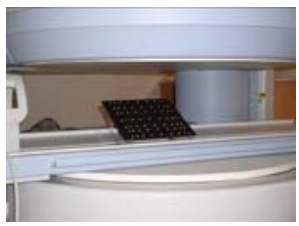

(a)

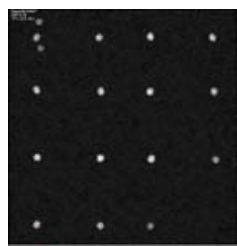

(b)

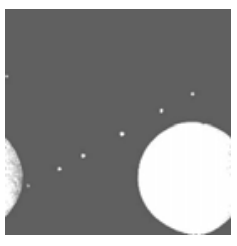

(c)

Fig. 3:

(a) The calibration frame used is composed of 64 spheres (diameter 5 $\mathrm{mm}$ ) visible on MR images, from which the 3D coordinates are computed.

(b) MR coronal slice

(c) MR axial slice

\section{E. Needle orientation}

Considering the needle tip on the insertion point (Fig. 4), the needle orientation was ensured by a stereovision system which detects the infrared LED set on the distal extremity. Using the epipolar constraint, at least two video cameras are used to compute 3D coordinates. The LED position is calculated in the MRI's coordinate system from the images obtained by the cameras. The pair of cameras given the lower epipolar error is dynamically chosen.

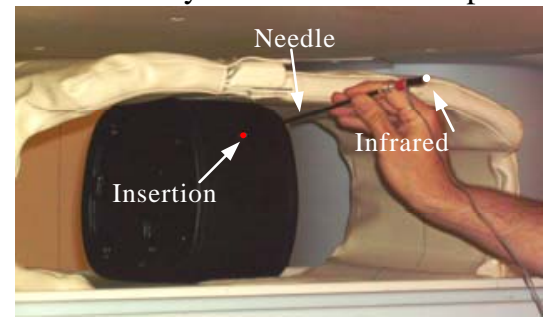

Fig. 4 Abdominal phantom and needle

A feedback is provided via a simple and intuitive computer interface (Fig. 5) displayed in the magnet room. So the surgeon was informed continuously of the needle position and of the overall targeting errors.
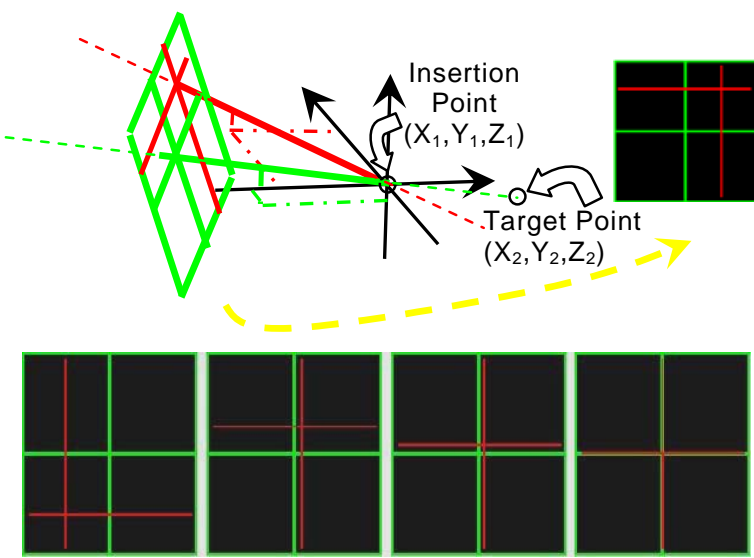

(a)

(b)

Fig.5 :

(a) 3D View of the interface displayed inside the magnet room

(b) Computer interface displayed in the scanner room using a projector

The green cross corresponds to the planned trajectory. (roadmap)

The red cross corresponds to the real needle trajectory.

\section{RESULTS}

To evaluate our system (Fig 6.), tests were carried out. First, the accuracy of the laser pointing device and of the stereovision system were evaluated. Then, the accuracy of the needle-insertion procedure was estimated. 


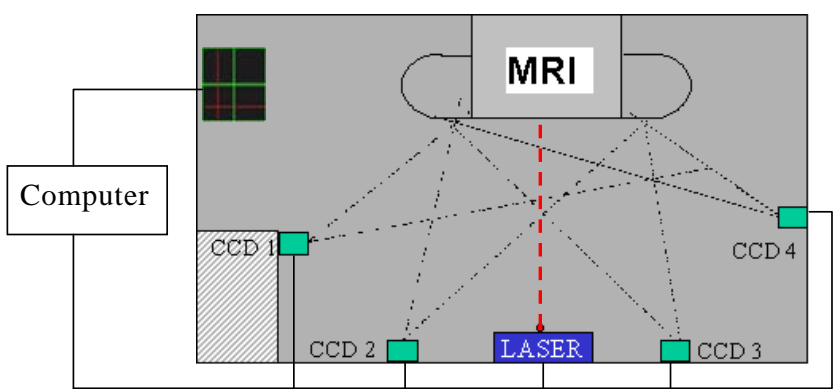

Fig. 6: Schematic summary, CCD video cameras and pen plotter disposition in the scanner room.

\section{A. Measurement of entry point error}

The mean error of the laser pointer displacement at 3 meters is less than $1 \mathrm{~mm}$ on both axes (Fig.7). Using the pen plotter calibration, the maximum uncertainty of the red spot (difference between desired and obtained 3D coordinate) is about $2 \mathrm{~mm}$. With regards to the size of the laser spot (about $3 \mathrm{~mm}$ diameter) this error is negligible. Time to enlighten the entry point by the laser spot on patient's skin is less than 1 second.

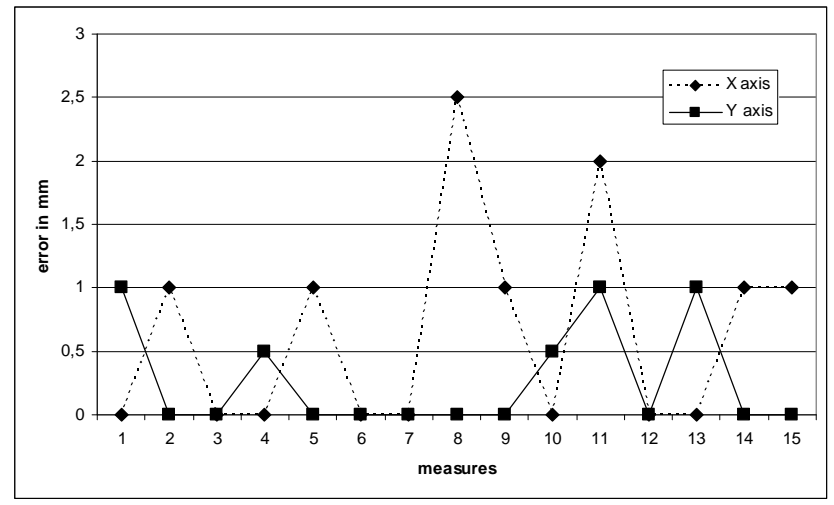

Fig. 7: 15 measures corresponding to 15 pointer displacements.

Mean error on $\mathrm{X}$ Axis : $0.63 \mathrm{~mm}( \pm 0.81$ range : $[0 ; 2.5])$

Mean error on Y Axis : $0.27 \mathrm{~mm}( \pm 0.41$ range : $[0 ; 1])$

\section{B. Evaluation of system calibration}

48 paired coordinates of the calibration frame were used to calculate the homogeneous matrix of each camera. Remaining points are backprojected on the video camera's image. Table 1 compared real and backprojected positions.

TABLE I

ERRORS OF CAMERA CALIBRATION

\begin{tabular}{lc}
\hline \hline & $\begin{array}{c}\text { Distance (pixel) between point } \\
\text { detected and backprojected }\end{array}$ \\
\hline Mean Error & 1.05 \\
Max Error & 1.36 \\
Min Error & 0.96 \\
Standard deviation & 0.10 \\
\hline \multicolumn{2}{c}{ Pixel size is about $0.65 \mathrm{~mm}$}
\end{tabular}

Pixel size is about $0.65 \mathrm{~mm}$

Combining the 2D information resulting from each camera, the stereovision system is able to measure the 3D positions of LEDs with an accuracy of about $0.2 \mathrm{~mm}$ at a rate of $24.192 \mathrm{MHz}$. The mean error between 3D coordinates ordered to the pen plotter and 3D coordinates observed by video cameras was computed. The obtained accuracy of the performances is about $3 \mathrm{~mm}(\mathrm{n}=15$ mean=3.5 $\mathrm{mm}$ and standard deviation $=1.5 \mathrm{~mm})$. 


\section{In situ evaluation of needle insertion}

The final error (depth of $10 \mathrm{~cm}$ under the skin) of the insertion needle procedure was evaluated using a multimodality interventional 3D abdominal phantom (http://www.cirsinc.com) (Fig.8). Procedure accuracy was about 6 $\mathrm{mm}$.

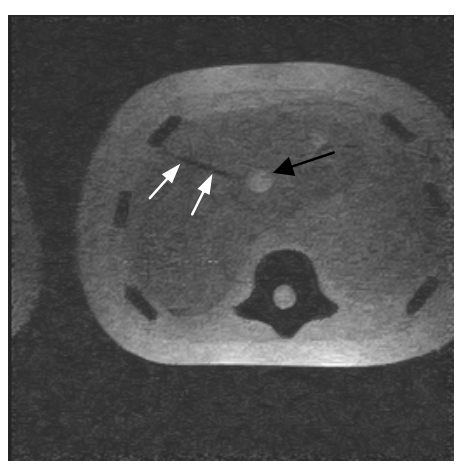

Fig. 8: An axial image of the abdominal phantom after needleinsertion procedure.

White arrows design the needle path (hyposignal)

Black arrow designs the target volume.

\section{Discussion}

To search for the entry point, physicians usually produces an artefact (eg, with a finger) on the patient's skin during nearly real-time image acquisition. However, the size of this artefact generally gives a great uncertainty of localization, which can induce major errors in trajectory planning. In fact, the trajectory of a needle can no longer be modified when it is inserted at a depth higher than approximately $2 \mathrm{~cm}$. MR fluoroscopic imaging can provide images (Frame rates greater than 10/sec) in the plane which contain the linear trajectory. In that way, next development will consist to track in real time the position of the needle tip, and to measure deviation between real trajectory and planned trajectory.

Under these conditions, the position of the needle insertion point and the direction of the needle must be given with a precision better than that which we wished at the level of the target point. Most application (i.e. biopsy, drainage, optical fibre guide, etc.) the targeting precision must be better than $5 \mathrm{~mm}$. Our proposed method of laser pointing allows an accurate determination of the entry point ( $2 \mathrm{~mm}$ accuracy). However, the success of in-vivo procedures could be compromised by geometric distortions of the images, if the needle entry point is outside the $\mathrm{B}_{0}$ homogeneity area where larger geometrics distortions may occur. In such case, three-dimensional coordinate correction has to be applied [10].

\section{CONCLUSION}

We have developed an original method to enlighten cutaneous points of interest with accuracy compatible with the surgical procedures. Laser indication system indicates to the physician the entry point on the skin. This technique permits to avoid the use of markers and provides a visual indication of the entry point with accuracy. In this way, it provides a quite practical solution to a common problem in interventional MRI procedures. Foreseen applications are at least double: on the first hand, the developed system can be adapted to any medical imaging modality and, on the other hand, this system can be used to guide rigid surgical tools during surgeries or complex therapeutic treatments such as Laser induced interstitial thermotherapy.

\section{ACKNOWLEDGMENT}

The assistance of HITACHI (J. Delannoy) is gratefully acknowledged. The authors would like to thanks Francois Cabestaing, and Maximilien Vermandel for their help and suggestions, as well as Pascal Briche and Marc Destombes for their technical assistance.

\section{REFERENCES}

[1] C. Ozturk, M. Guttman, E. R. McVeigh, and R. J. Lederman, "Magnetic Resonance Imaging-guided Vascular Interventions," Topics in Magnetic Resonance Imaging, vol. 16, no. 5, pp. 369-381, 2005. 
[2] C. M. Hillenbrand, D. R. Elgort, E. Y. Wong, A. Reykowski, F. K. Wacker, J. S. Lewin, and J. L. Duerk, "Active device tracking and high-resolution intravascular MRI using a novel catheter-based, opposed-solenoid phased array coil," Magn Reson. Med., vol. 51, no. 4, pp. 668-675, Apr.2004.

[3] C. J. Bakker, C. Bos, and H. J. Weinmann, "Passive tracking of catheters and guidewires by contrast-enhanced MR fluoroscopy," Magn Reson. Med., vol. 45, no. 1, pp. 17-23, Jan.2001.

[4] G. P. Penney, J. M. Blackall, M. S. Hamady, T. Sabharwal, A. Adam, and D. J. Hawkes, "Registration of freehand 3D ultrasound and magnetic resonance liver images," Med. Image Anal., vol. 8, no. 1, pp. 81-91, Mar.2004.

[5] S. Zangos, C. Herzog, K. Eichler, R. Hammerstingl, A. Lukoschek, S. Guthmann, B. Gutmann, U. J. Schoepf, P. Costello, and T. J. Vogl, "MR-compatible assistance system for punction in a high-field system: device and feasibility of transgluteal biopsies of the prostate gland," Eur. Radiol., vol. 17, no. 4, pp. 1118-1124, Apr.2007.

[6] K. Cleary, A. Melzer, V. Watson, G. Kronreif, and D. Stoianovici, "Interventional robotic systems: applications and technology stateof-the-art," Minim. Invasive. Ther. Allied Technol., vol. 15, no. 2, pp. 101-113, 2006.

[7] R. Y. Tsai, A versatile camera calibration technique for high accuracy 3D machine vision metrology using Off-the-Shelf TV cameras and lenses, IEEE Journal of Robotics and Automation RA-3 (4), 1987,323-344.

[8] E. Ballet, J. Rousseau, D. Gibon, J.F. Cussac, C. Vasseur, X. Marchandise, Mise en correspondance d'images scintigraphiques et échographiques de la thyroïde par une méthode de vision stéréoscopique, Médecine Nucléaire, 21 (7), $1997,409-414$.

[9] N. Betrouni, G. Palos, M. Vermandel, S. Maouche, and J. Rousseau, "A New System for Freehand Ultrasound Tracking Application in Multimodality Image Matching,".

[10] V. Daanen, E. Coste, G. Sergent, F. Godart, C. Vasseur, and J. Rousseau, "Accurate localization of needle entry point in interventional MRI," J. Magn Reson. Imaging, vol. 12, no. 4, pp. 645-649, Oct. 2000. 